\title{
CENTRAL OBESITY INFLUENCES JOINT PAIN SEVERITY IN OSTEOARTHRITIS AND RHEUMATOID ARTHRITIS CASES INDEPENDENT OF BODY MASS INDEX
}

Karoline Ribeiro Rosa ${ }^{1}$, Martha Cecilia Castaño-Betancourt ${ }^{1, \star}$, Catrine Rangel Maia ${ }^{1}$, Monica Vannucci Nunes Lipay ${ }^{1}$, Evaldo Marchi ${ }^{1}$

1.Faculdade de Medicina de Jundiaí, Jundiaí (SP), Brazil.

*Corresponding author: castanomc@yahoo.es

\section{BACKGROUND.}

Rheumatoid arthritis (RA) and osteoarthritis (OA) are the most common joint diseases with different pathophysiology and shared aspects. Obesity and components of the metabolic syndrome (MetS) have been considered as risk factors for RA and OA. Metabolic syndrome is a cluster of cardiometabolic disorders that includes central obesity between others. We aim to determine whether central obesity, plays a role in the onset of joint pain and pain severity in patients with OA and RA, independent of body mass index (BMI).

\section{MATERIALS/METHODS}

We examined medical records and interviewed 771 patients with confirmed diagnoses of $O A$ and 92 patients with RA who attended the orthopedics outpatient clinic, referred from other services due to advanced joint wear on the hip and/or knee and persistent joint pain. We determined the age of OA and RA onset in years, joints affected by pain using the Numerical Rating Scale (NRS), and walking disability (without difficulty vs. with difficulty or unable). Waist and hip circumferences were measured, and central obesity (waist/ hip ratio) was defined as healthy or not according to the World Health Organization (WHO). Linear and logistic regression analyses $(\beta)$ and odds ratio $(\mathrm{OR})$ with $95 \%$ confidence interval $(\mathrm{Cl})$ and analysis of variance (ANOVA), adjusted for age, gender, and $\mathrm{BMI}$.

\section{RESULTS}

Unhealthy central obesity was associated with an earlier onset of OA-symptoms ( 2 years difference, $p=0.04$ ). Central obesity was not significant regarding the age of onset of RA-symptoms $(p=0.85)$. However, central obesity was associated with more joints affected by pain and a higher level of joint pain by NRS in females with $R A(O R=1.53, C l=1.03-2.28$, and $O R=1.44$, $\mathrm{Cl}=1.04-2.0$, respectively). In subjects with $\mathrm{OA}$ and $\mathrm{RA}$, wider waist circumference was associated with a higher level of pain, principally in females $(\beta=0.44, p=0.004$ and $\beta=0.87, p=0.06$ for all subjects with $O A$ and $R A$ and $\beta=0.92, p=0.048$ and $\beta=0.52, p=0.006$ for females with $O A$ and $R A$ respectively). A higher level of pain is associated with walking disability ( $O R=1.34$, $\mathrm{Cl}=1.24-1.44)$. All these associations were independent of BMI.

\section{CONCLUSIONS}

Central obesity is a factor associated with pain severity and the number of joints affected in both, RA and OA cases and the age of OA-symptoms onset. Pain directly influenced the level of disability. Adipose tissue is not merely an inert energy store but an endocrine organ that facilitates pro-inflammatory factors production and therefore may be involved in the process of joint inflammation, disease progression, and pain for both, OA, and RA.

\section{ACKNOWLEDGEMENTS}

The São Paulo Research Foundation (FAPESP), Process number 2016/21039-0 and process number 2019/21326-8. 